\title{
Study on the Preparation and Anisotropic Distribution of Mechanical Properties of Well-Aligned PMIA Nanofiber Mats Reinforced Composites
}

\author{
Bin He, Dongyi Tan, Tao Liu, Zexing Wang, and Hengshu Zhou \\ Institute of Textile and Fashion, Hunan Institute of Engineering, No. 88, East Fuxing Road, Yuetang District, Xiangtan City, \\ Hunan Province 411104, China
}

Correspondence should be addressed to Bin He; hb126_b@163.com

Received 16 January 2017; Revised 22 February 2017; Accepted 23 February 2017; Published 8 March 2017

Academic Editor: Yves Grohens

Copyright (C) 2017 Bin He et al. This is an open access article distributed under the Creative Commons Attribution License, which permits unrestricted use, distribution, and reproduction in any medium, provided the original work is properly cited.

Well-aligned PMIA nanofiber mats were fabricated by electrospinning and then hot-pressing was used to produce PMIA nanofiber mats reinforced PLA matrix by layer-by-layer with the interlayer angles of 0,45 , and $90^{\circ}$. Orthogonal experimental design was employed to fix the effect of the hot-pressing parameters on the tensile strength of nanocomposites, and SEM was used to characterize the broken sections of the nanocomposites after tensile test. The optimized process parameters were achieved of pressure as $1000 \mathrm{~Pa}$, temperature as $180^{\circ} \mathrm{C}$, and time as $30 \mathrm{~min}$. The SEM images of broken sections showed that the different laminate forms and the state of bearing load of nanofibers resulted in the different morphologies of broken sections. The break strength of PMIA/PLA nanocomposites with any of interlayer angles at different tensile testing directions was revealed as follows: axial > oblique $>$ transverse, and the initial modulus also showed the same except the angle of $90^{\circ}$ with the approach initial modulus at the axial and transverse directions. The maximum tensile strength and modulus of the nanocomposites were 17.12 MPa and $1642.17 \mathrm{MPa}$, respectively, of the axial tensile testing directions of the interlayer angle of $0^{\circ}$.

\section{Introduction}

Traditional high performance fibers such as glass, carbon, and aramid fibers are to be used as reinforcements in the polymer matrix composites widely $[1,2]$. These fibers reinforced polymer composites exhibit superior structural properties such as high strength-to-weight and stiffness-toweight ratios and the ability in providing both mechanical and functional performances, which induced them to be used on many fields $[2,3]$. There are many factors that can affect the properties of fibers reinforced polymer composites, in which one is interfacial characteristics. Strong adhesion between reinforcing fibers and polymer matrix is the prerequisite for transferring load sufficiently from matrix to fibers. Compared to traditional fibers, nanofibers have a large specific surface area, which can provide more interaction between reinforcing fibers and polymer matrix and enables the applied load to be transferred on fibers-matrix interface, and lead to an improvement on the properties of the composites $[4,5]$.
The resultant polymer nanofibers assembled by electrospinning are featured on large specific surface area, and it can enable the applied load to be transferred on nanofibersmatrix interface [6-10]. Some researchers have attempted to manufacture nanocomposites reinforced with electrospun polymer nanofibers [11-18]. Among them, Uyar et al. [12] have used electrospun polyvinyl alcohol (PVA) to reinforce the polymethylmethacrylate (PMMA) composites resins, and their results indicated that the mechanical properties of PMMA composites were improved, and the improvement was higher when aligned PVA nanofibers are used. The maximum values were $5.1 \mathrm{MPa}$ (flexural strength), $0.8 \mathrm{GPa}$ (elastic modulus), and $170 \mathrm{~kJ} / \mathrm{m}^{3}$ (toughness) in three-point bending test. Chen et al. [16] have used the well-aligned electrospun polyimide (PI) nanofibers containing carbon nanotubes (CNTs) as homogeneity reinforcement to enhance the tensile strength and toughness of PI films. Compared with neat PI film prepared by solution casting, the tensile strength and elongation at break in the PI film reinforced with 

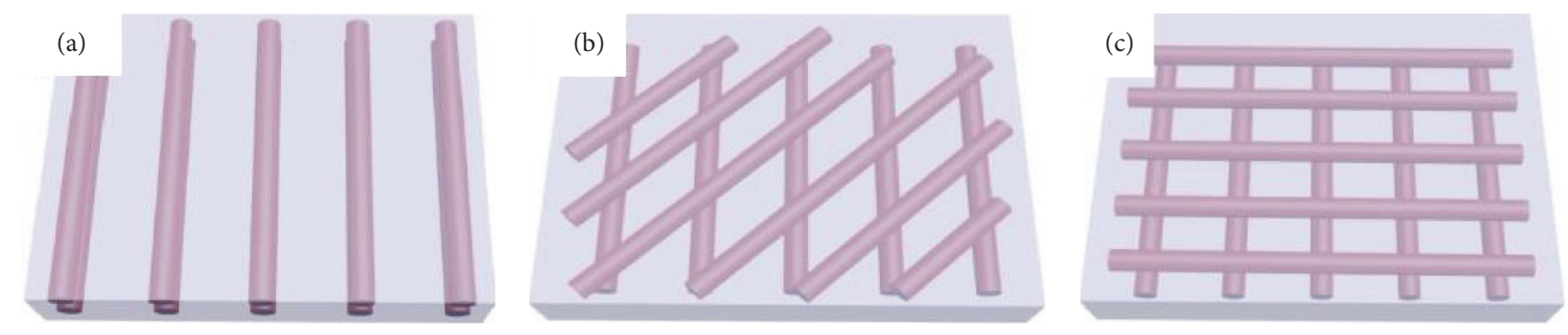

Figure 1: Schematic drawings of layer-by-layer of aligned fibers with different interlayer angles of $0^{\circ}$ (a), $45^{\circ}$ (b), $90^{\circ}$ (c).

CNTs/PI nanofibers were remarkably increased by $138 \%$ and $104 \%$, respectively.

Poly(m-phenylene isophthalamide) (PMIA) has especially prominent thermostability, high flame retardant, selfextinguishing characteristics, electrical insulation ability, chemical resistance, mechanical properties, and so forth. So it is widely applied to special protective clothing, high temperature filter materials, electrical insulating materials, honeycomb structure wainscoting materials, and so forth [1921]. Our group successfully manufactured PMIA nanofibers with excellent morphology by electrospinning [22], and following the previous work, well-aligned electrospun PMIA nanofiber mats were fabricated and then hot-stretching along the fiber axis was used to improve the mechanical properties of nanofibers [23]. Polylactic acid (PLA) is a thermoplastic, biodegradable, and renewable polymer, which is industrially obtained, respectively, through the polymerization of lactic acid or by the ring-opening polymerization of lactide. Some researches showed that PLA has gained enormous attention as an alternative to petrochemical-based synthetic polymers in packaging and/or textile sectors at present. The production of PLA composites is realized using the following techniques mainly: (a) melt-compounding, (b) solvent-based, (c) pultrusion, (d) coextrusion (fibers, films, and sheets), and (e) hot-pressing (film stacking). Among them, techniques of (c), (d), and (e) are usually used to produce fiber reinforced PLA composites [24-26].

Processing parameters significantly influence the properties and interfacial characteristics of the composites. Therefore, suitable processing parameters must be carefully selected in order to yield the optimum composite products. In this study, well-aligned electrospun PMIA nanofiber mats were produced, which have been used to reinforce the PLA matrix by layer-by-layer with the interlayer angles of 0,45 , and $90^{\circ}$. Orthogonal experimental design was employed to fix the effect of the hot-pressing parameters on the tensile strength of nanocomposites. The tensile mechanical properties were evaluated on the axial, transverse, and oblique directions of the nanocomposites, respectively, and the effects of the interlayer angles on the tensile mechanical strength were investigated in detail.

\section{Materials and Methods}

2.1. Materials. Commercial PMIA fibers (tensile strength at breakage was ca. $4.5 \mathrm{cN} /$ dtex and density $1.37-1.38 \mathrm{~g} / \mathrm{cm}^{3}$ ) were provided by Yantai Spandex Co. Ltd. (China). PLA (PLLA, $\overline{\mathrm{Mw}} \approx 170000$ ) was supplied by W.W Plastic Ningbo Co. Ltd. (China). DMAc was purchased from J\&K Scientific Co. Ltd. Anhydrous lithium chloride $(\mathrm{LiCl})$ was supplied by Shanghai Jufeng Chemical Scientific Co. Ltd. (China). Dichloromethane was purchased from Sinopharm Chemical Reagent Co., Ltd. (China). All the chemicals were of analytical reagent grade.

2.2. Preparation of Electrospun Nanofiber Mats. Firstly, the spinning solution was prepared with the mass fractions of PMIA and $\mathrm{LiCl}$ in the solution being $12 \%$ and $6 \%$, respectively. Then the well-aligned electrospun PMIA nanofiber mats were fabricated by electrospinning on the Nanofiber Electrospinning Unit made by KATO TECH Co. Ltd., Japan. Spinning parameters were as follows: inner diameter of spinneret $0.45 \mathrm{~mm}$, voltage $23 \mathrm{kV}$, collecting spinning distance $11 \mathrm{~cm}$, solution flow rate $0.26 \mathrm{~mL} \cdot \mathrm{h}^{-1}$, spinneret scan speed $14 \mathrm{~cm} \cdot \mathrm{min}^{-1}$, and collector rotating speed $6 \mathrm{~m} \cdot \mathrm{min}^{-1}$. The detailed steps were described in our previous work [23].

2.3. Preparation of Prepregs. Firstly, the PLA was added to dichloromethane and stirred till it was dissolved completely with the mass fractions of PLA being about 3 4\%; then the well-aligned PMIA nanofiber mats $(50 \mathrm{~mm} \times 40 \mathrm{~mm})$ were laminated into the solution layer-by-layer (2 layers of nanofiber mats were deposited) with the interlayer angles of 0,45 , and $90^{\circ}$, respectively, as shown in Figure 1 . Then the solvent evaporated at room temperature and gained the prepregs.

\subsection{Optimization of the Process Parameters of Hot-Pressing by} Orthogonal Experimental Design. Orthogonal experimental design was employed to fix the effect of the process parameters on the tensile strength of nanocomposites. Take the nanocomposites of interlayer angles of $0^{\circ}$ as an example, and the tensile test progressed along the axial direction. The nanocomposites obtained finally with the thickness of $0.230 \pm 0.020 \mathrm{~mm}$ and the mass fractions of nanofibers in nanocomposites were about $20 \%$. The three parameters of the hot-pressing process were selected as the test factors: hotpressing pressure, temperature, and time, and three levels were set for each factor. The pressure $(P)$ was set at $600(\mathrm{~A} 1)$, 1000 (A2), and 1400 (A3) Pa; the temperature (T) was 175 (B1), $180(\mathrm{~B} 2)$, and $185(\mathrm{~B} 3)^{\circ} \mathrm{C}$; the time $(t)$ was $25(\mathrm{C} 1), 20(\mathrm{C} 2)$, 
TABLE 1: Design of experiment and measurement results of each index.

\begin{tabular}{|c|c|c|c|c|c|c|}
\hline \multirow{2}{*}{ Experiment number } & \multirow{2}{*}{$\mathrm{A}(P / \mathrm{Pa})$} & \multirow{2}{*}{$\mathrm{B}\left(T /{ }^{\circ} \mathrm{C}\right)$} & \multirow{2}{*}{$\mathrm{C}(t / \mathrm{min})$} & \multirow{2}{*}{ Blank } & \multicolumn{2}{|c|}{ Tensile strength/MPa } \\
\hline & & & & & I & II \\
\hline 1 & 1 & 1 & 1 & 1 & $7.397 \pm 0.78$ & $7.412 \pm 0.77$ \\
\hline 2 & 1 & 2 & 2 & 2 & $8.560 \pm 0.86$ & $8.561 \pm 0.85$ \\
\hline 3 & 1 & 3 & 3 & 3 & $9.140 \pm 0.85$ & $9.126 \pm 0.88$ \\
\hline 4 & 2 & 1 & 2 & 3 & $10.152 \pm 0.92$ & $10.161 \pm 0.90$ \\
\hline 5 & 2 & 2 & 3 & 1 & $13.026 \pm 0.88$ & $13.018 \pm 0.87$ \\
\hline 6 & 2 & 3 & 1 & 2 & $10.988 \pm 0.93$ & $10.980 \pm 0.93$ \\
\hline 7 & 3 & 1 & 3 & 2 & $8.869 \pm 0.89$ & $8.870 \pm 0.90$ \\
\hline 8 & 3 & 2 & 1 & 3 & $7.175 \pm 0.78$ & $7.172 \pm 0.76$ \\
\hline 9 & 3 & 3 & 2 & 1 & $7.232 \pm 0.75$ & $7.228 \pm 0.78$ \\
\hline
\end{tabular}

TABLE 2: Analysis of variance of tensile strength.

Test of between-subjects effects

Dependent variable: intensity

\begin{tabular}{ccccr} 
Source & $\begin{array}{c}\text { Type III } \\
\text { sum of } \\
\text { squares }\end{array}$ & df & Mean square & $F$ \\
\hline Corrected model & $59.573^{\mathrm{a}}$ & 6 & 9.929 & 84.648 \\
Intercept & 1513.729 & 1 & 1513.729 & 12905.256 \\
A & 45.350 & 2 & 22.675 & .000 \\
B & 1.830 & 2 & .915 & .000 \\
C & 12.393 & 2 & 6.196 & .000 \\
Error & 1.290 & 11 & .117 & .008 \\
Total & 1574.592 & 18 & & .000 \\
Corrected total & 60.863 & 17 & & \\
\hline
\end{tabular}

${ }^{\mathrm{a}} R$-squared $=.979($ adjusted $R$-squared $=.967)$.

and 30 (C3) min, respectively. The experiment was repeated twice. Table 1 showed the orthogonal table $\mathrm{L}_{9}(3)^{4}$, and SPSS data software was used to analyze the experimental data by variance analysis and Duncan's multiple range test.

\subsection{Preparation of Hot-Pressed Nanofiber Mats Reinforced} Composites. The prepregs with different interlayer angles were hot-pressed at the optimized process parameters and trimmed their sides carefully after cooling under the room temperature. The nanocomposites obtained finally with the thickness of $0.290 \pm 0.020 \mathrm{~mm}$ and the mass fractions of nanofibers in nanocomposites were about $39 \%$, for the reason was that the mechanical properties of the nanocomposites reached the maximum value when the nanofibers content in the nanocomposites was about $39 \mathrm{wt} \%$ by changing the nanofibers content at the optimized process parameters.

2.6. Measurements. The mechanical properties of the nanocomposites were tested by Instron 5967 mechanical testing machine with gauge length $20 \mathrm{~mm}$ and crosshead speed $20 \mathrm{~mm} / \mathrm{min}$. The tensile test progressed along the axial (parallel to the aligned fibers), transverse (perpendicular to the aligned fibers), and oblique ( $45^{\circ}$ bias to the aligned fibers) directions, respectively. The sample amount was 5 for each sample, and the sample was cut into dumbbells showed in Figure 2. The tensile strength at breakage was calculated by the mean of 5 samples. All of the samples were conditioned in a laboratory environment $\left(20 \pm 1^{\circ} \mathrm{C}\right.$ and $\left.65 \pm 3 \%\right)$ for $24 \mathrm{~h}$ before testing.

The morphologies of the broken sections of the nanocomposites after the tensile test were observed by scanning electron microscopy (SEM) (Hitachi S-4800, Japan).

\section{Results and Discussion}

3.1. Optimization of the Process Parameters of Hot-Press. Table 1 shows the measurement results of each index and Table 2 shows the result of variance analysis. It is clear that all the significance levels (Sig.) of the three factors A (pressure), B (temperature), and C (time) were less than 0.01 , which indicated that all the three factors have the extreme influence on the tensile strength of nanocomposites. Duncan's multiple range test of the three factors was exhibited in Table 3. The results illustrated that all the Sig. of the three levels of each factor were more than 0.01 , so it meant that there was no significant difference among the levels on the tensile strength. Therefore, the level of each factor was 


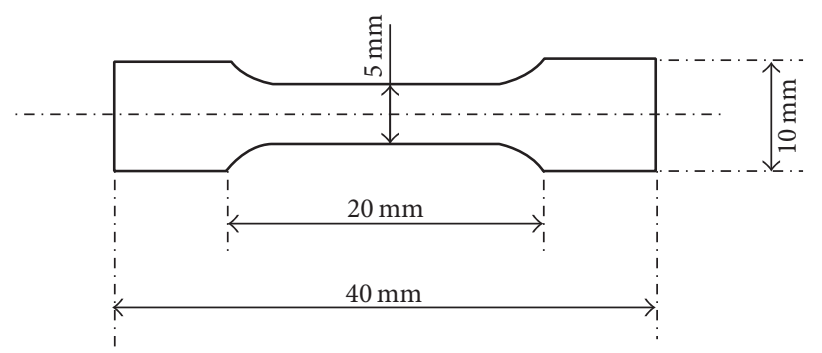

Figure 2: The sample diagram of tensile test.

TABLE 3: Duncan's multiple range test of (a) pressure, (b) temperature, and (c) time.

(a)

\begin{tabular}{lcccc}
\hline \multicolumn{4}{c}{ Duncan $^{\mathrm{a}, \mathrm{b}}$} & \multicolumn{2}{c}{ Intensity } & \\
$\mathrm{A}$ & $N$ & & Subset & \\
& & 1 & 2 & 3 \\
\hline 3.00 & 6 & 7.75676 & & \\
1.00 & 6 & & 8.36600 & \\
2.00 & 6 & & & 11.38750 \\
Sig. & & 1.000 & 1.000 & 1.000 \\
\hline
\end{tabular}

(b)

\begin{tabular}{lccc}
\hline & \multicolumn{3}{c}{ Intensity } \\
& Duncan $^{\mathrm{a}, \mathrm{b}}$ & & \multicolumn{2}{c}{ Subset } \\
B & $N$ & 1 & 2 \\
\hline 1.00 & 6 & 8.81017 & \\
3.00 & 6 & 9.11567 & \\
2.00 & 6 & & 9.58533 \\
Sig. & & .151 & 1.000 \\
\hline
\end{tabular}

(c)

\begin{tabular}{lccc}
\hline & \multicolumn{3}{c}{ Intensity } \\
Cuncan & & \multicolumn{2}{c}{ Subset } \\
& $N$ & 1 & 2 \\
\hline 1.00 & 6 & 8.52067 & \\
2.00 & 6 & 8.64900 & \\
3.00 & 6 & & 10.34150 \\
Sig. & & .530 & 1.000 \\
\hline
\end{tabular}

Means for groups in homogeneous subsets are displayed.

Based on type III sum of squares, the error term is mean square (error) $=.117$

${ }^{a}$ Using harmonic mean sample size $=6.000$.

${ }^{\mathrm{b}}$ Alpha $=.05$.

selected in which the nanocomposites with the highest tensile strength were fabricated, so the levels of the three factors were selected: pressure A2 (Table 3(a)), temperature B2 (Table 3(b)), and time C3 (Table 3(c)). Finally the optimized process parameters of hot-pressing were achieved as follows: pressure as $1000 \mathrm{~Pa}$, temperature as $180^{\circ} \mathrm{C}$, and time as $30 \mathrm{~min}$.
3.2. Morphologies of the Broken Sections. Figure 3 shows SEM images of the broken sections of the nanocomposites after the tensile test, and the inserted image is the magnified parts. The nanofibers revealed excellent morphologies, which demonstrated that the hot-pressing process did not damage the nanofibers figuration. On crack of PLA matrix, nanofibers were pulled out and fracture of PLA and fracture of nanofibers occurred when tensile testing. The alignment state of nanofibers with different interlayer angles was displayed clearly through the broken sections. For the interlayer angles of $0^{\circ}$ (Figure 3(a)), the aligned nanofibers were perpendicular to the broken section and adhered to the PLA matrix on crack when axial tensile testing. On the contrary, the aligned nanofibers parallel to the broken section and there were hardly nanofibers adhered to the PLA matrix on crack when transverse tensile testing. For the reason is that the tensile direction was along the aligned nanofibers axis when axial tensile testing, then the nanofibers suffered the primary load transferred from the matrix, while the tensile direction was perpendicular to the aligned nanofibers axis when transverse tensile testing, and the nanofibers were unable to undertake the load. For $45^{\circ}$ (Figure 3(b)), the broken sections of axial and oblique tensile testing appeared a certain step-shaped, even a slip plane emerged in the transverse broken section. This is probably because the double nanofibers mats bore the load together at axial and oblique tensile testing, the aligned nanofibers axis of which along the tensile direction suffered a greater load than the other, that induced the emergence of step. While only one nanofibers mat undertook partial load when transverse tensile testing, the matrix surrounding the nanofibers which could not bear the load was easy to slip when stretching. For $90^{\circ}$ (Figure 3(c)), the morphologies of the broken sections of axial and transverse tensile testing were similar for the reason was that the nanofibers were arranged perpendicularly to intersect, and a slip plane appeared on the broken sections, for they had the same force way when stretching. In a word, the different laminate forms and the state of bearing load of nanofibers resulted in the different morphologies of broken sections.

3.3. Mechanical Properties. The obtained PMIA/PLA nanocomposites reinforced by the aligned nanofiber mats deposited by layer-by-layer with interlayer angles will exhibit anisotropic distribution of mechanical properties. Figure 4 shows the tensile strength at break, initial modulus, and elongation at break of nanocomposites at the tensile testing 


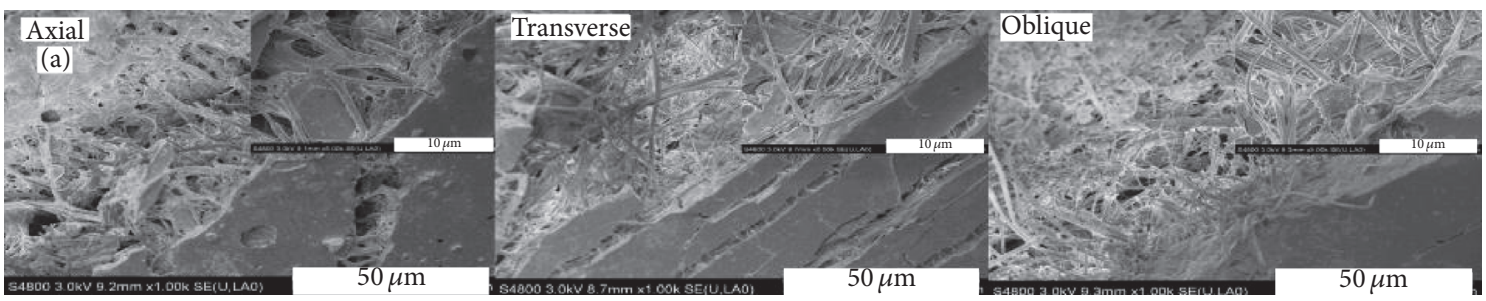

(a)

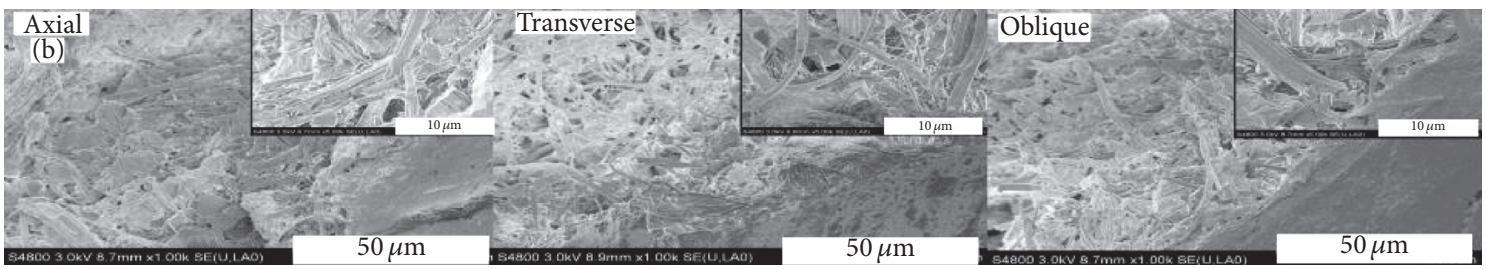

(b)

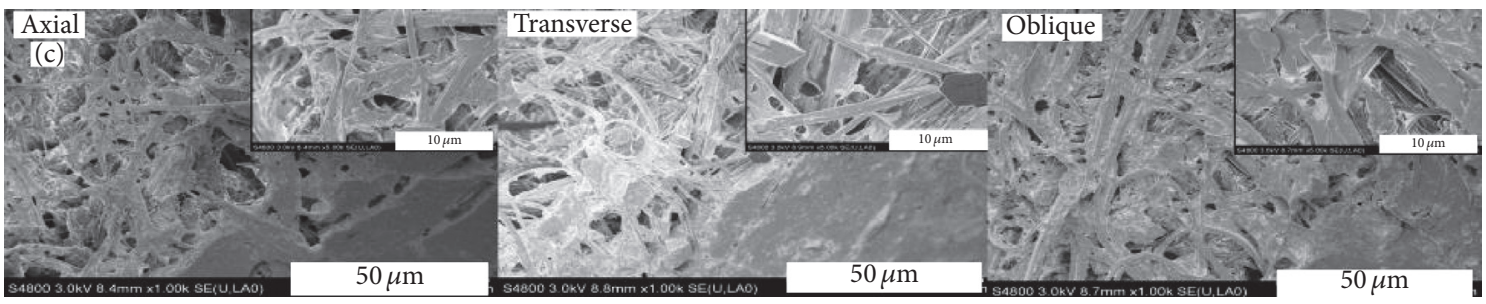

(c)

FIGURE 3: SEM images of the broken sections of the nanocomposites after the tensile test: the interlayer angles of (a) $0^{\circ}$, (b) $45^{\circ}$, and (c) $90^{\circ}$.

directions of axial, transverse, and oblique. Figure 5 shows the mechanical properties of nanofiber mats and pure PLA which is produced by the same method of nanocomposites. The results indicated that the break strength of PMIA/PLA nanocomposites with any of interlayer angles at different tensile testing directions is revealed as follows: axial > oblique $>$ transverse, and the modulus also showed the same except the angle of $90^{\circ}$ with the approach modulus at the axial and transverse directions. The break strength of PMIA/PLA nanocomposites along the axial direction decreased with increasing the interlayer angles, while that along the transverse direction increased gradually and that along the oblique direction increased first and then decreased. The maximum tensile strength and initial modulus of the nanocomposites were $17.12 \mathrm{MPa}$ and $1642.17 \mathrm{MPa}$, respectively, of the axial tensile testing directions of $0^{\circ}$. The tensile strength and initial modulus of the nanocomposites peaked at ca. 205\% and ca. $169 \%$, respectively, compared with the pure PLA. From the structural point of view, the axial structure is able to transmit forces along its tensile directions, so the distributed tensile mechanical properties of nanocomposites are according to the fiber arrangement and fiber orientation angles. The crosslinking structure centered the strength along the tensile direction, although the interlayer angles existed on the fibers tensile direction.

\section{Conclusions}

Well-aligned PMIA nanofiber mats were fabricated by electrospinning, which had been used to reinforce the PLA matrix by layer-by-layer with the interlayer angles of 0,45 , and $90^{\circ}$ by hot-pressing. Orthogonal experimental design was employed to fix the effect of the hot-pressing parameters on the tensile strength of nanocomposites. The optimized process parameters were achieved of pressure $1000 \mathrm{~Pa}$, temperature $180^{\circ} \mathrm{C}$, and time $30 \mathrm{~min}$. The SEM images of broken sections of the nanocomposites after the tensile testing showed that the different laminate forms and the state of bearing load of nanofibers resulted in the different morphologies of broken sections. The break strength of PMIA/PLA nanocomposites with any of interlayer angles at different tensile testing directions was revealed as follows: axial $>$ oblique $>$ transverse, and the modulus also showed the same except the angle of $90^{\circ}$ with the approach modulus at the axial and transverse directions. The maximum tensile strength and modulus of the nanocomposites were $17.12 \mathrm{MPa}$ and $1642.17 \mathrm{MPa}$, respectively, of the axial tensile testing directions of the interlayer angle of $0^{\circ}$.

\section{Conflicts of Interest}

The authors declare that they have no conflicts of interest. 


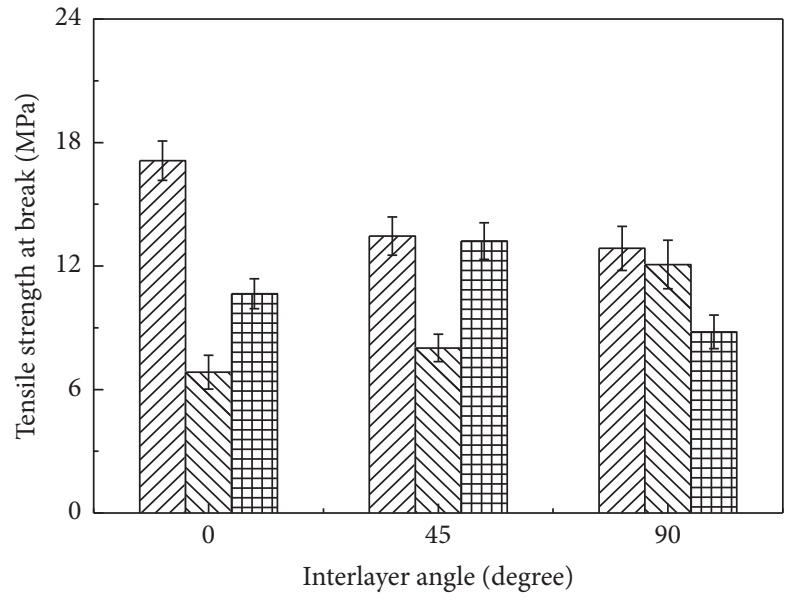

EZI Axial חIV Transverse 回 Oblique

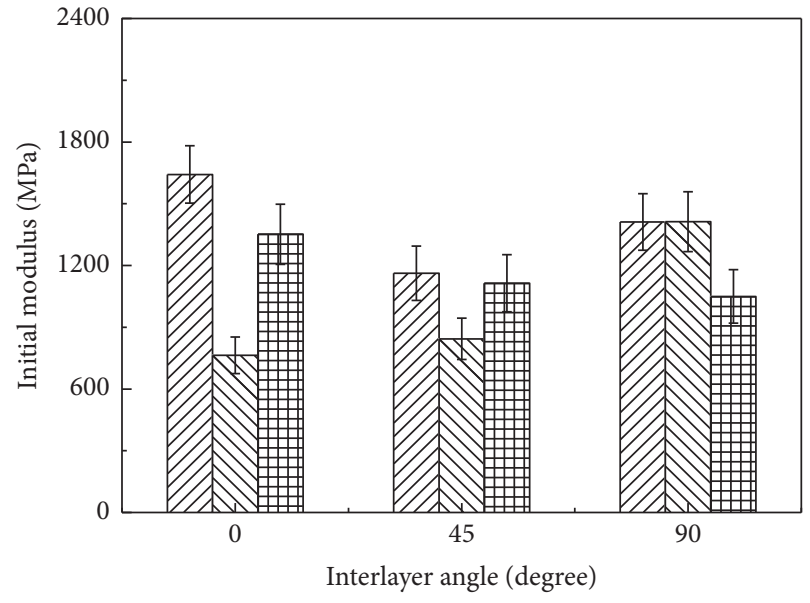

EZI Axial

WIV Transverse 巴四 Oblique

(a) (b)

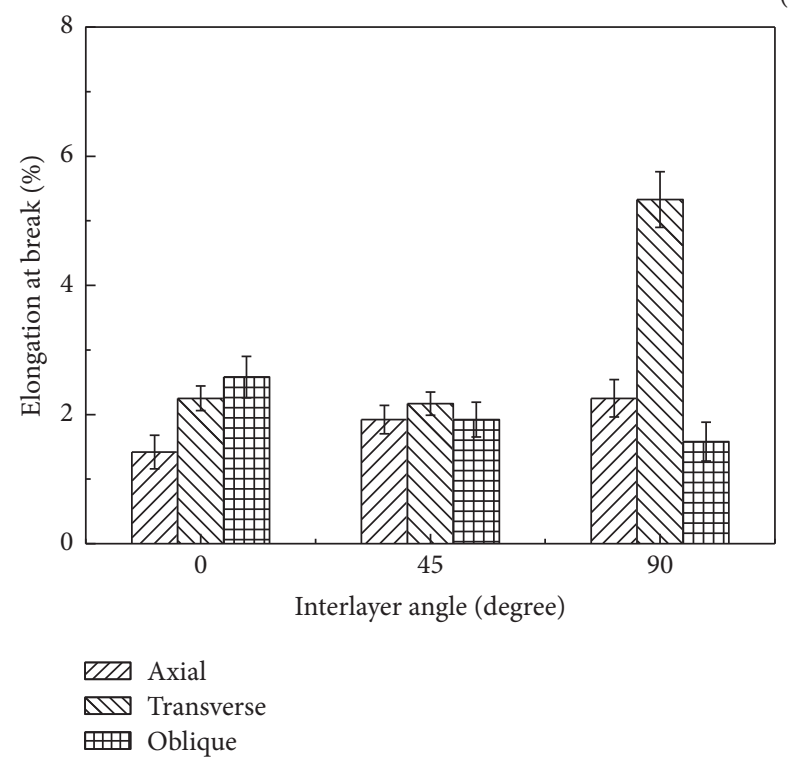

(c)

FIGURE 4: Mechanical properties of nanocomposites: tensile strength (a), initial modulus (b), and elongation (c).

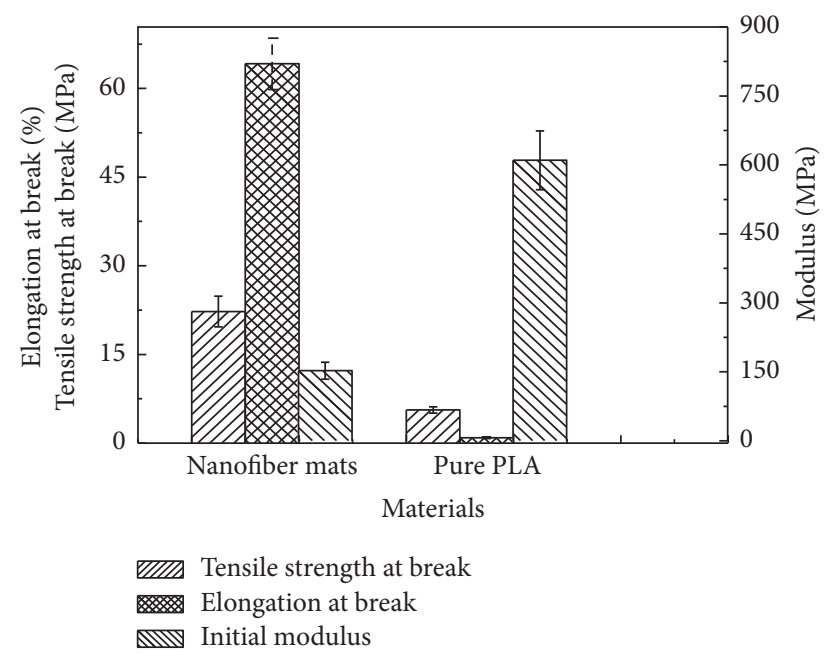

FIGURE 5: Mechanical properties of nanofiber mats and pure PLA.

\section{Acknowledgments}

This work was supported by Provincial Natural Science Foundation of Hunan [2015JJ6023] and by the Doctoral Scientific Research Foundation of Hunan Institute of Engineering [14082, 14093].

\section{References}

[1] H. Ku, H. Wang, N. Pattarachaiyakoop, and M. Trada, "A review on the tensile properties of natural fiber reinforced polymer composites," Composites Part B: Engineering, vol. 42, no. 4, pp. 856-873, 2011.

[2] E. Asmatulu, J. Twomey, and M. Overcash, "Recycling of fiberreinforced composites and direct structural composite recycling concept," Journal of Composite Materials, vol. 48, no. 5, pp. 593608, 2014. 
[3] L. Liu, Z.-M. Huang, C. L. He, and X. J. Han, "Mechanical performance of laminated composites incorporated with nanofibrous membranes," Materials Science and Engineering A, vol. 435-436, pp. 309-317, 2006.

[4] D. W. Schaefer and R. S. Justice, "How nano are nanocomposites?” Macromolecules, vol. 40, no. 24, pp. 8501-8517, 2007.

[5] S. Lin, Q. Cai, J. Ji et al., "Electrospun nanofiber reinforced and toughened composites through in situ nano-interface formation," Composites Science and Technology, vol. 68, no. 1516, pp. 3322-3329, 2008.

[6] Z.-M. Huang, Y.-Z. Zhang, M. Kotaki, and S. Ramakrishna, "A review on polymer nanofibers by electrospinning and their applications in nanocomposites," Composites Science and Technology, vol. 63, no. 15, pp. 2223-2253, 2003.

[7] C. J. Angammana and S. H. Jayaram, "Fundamentals of electrospinning and processing technologies," Particulate Science and Technology, vol. 34, no. 1, pp. 72-82, 2016.

[8] A. Baji, Y.-W. Mai, S.-C. Wong, M. Abtahi, and P. Chen, "Electrospinning of polymer nanofibers: effects on oriented morphology, structures and tensile properties," Composites Science and Technology, vol. 70, no. 5, pp. 703-718, 2010

[9] M. Mirjalili and S. Zohoori, "Review for application of electrospinning and electrospun nanofibers technology in textile industry," Journal of Nanostructure in Chemistry, vol. 6, no. 3, pp. 207-213, 2016.

[10] D. H. Reneker, A. L. Yarin, E. Zussman, and H. Xu, "Electrospinning of nanofibers from polymer solutions and melts," Advances in Applied Mechanics, vol. 41, pp. 43-346, 2007.

[11] G. Li, X. Jia, Z. Huang et al., "Prescribed morphology and interface correlation of MWNTs-EP/PSF hybrid nanofibers reinforced and toughened epoxy matrix," Materials Chemistry and Physics, vol. 134, no. 2-3, pp. 958-965, 2012.

[12] T. Uyar, D. Cökeliler, M. Doğan, I. C. Koçum, O. Karatay, and E. B. Denkbaş, "Electrospun nanofiber reinforcement of dental composites with electromagnetic alignment approach," Materials Science and Engineering C, vol. 62, pp. 762-770, 2016.

[13] Y. Kim, R. Jung, H.-S. Kim, and H.-J. Jin, "Transparent nanocomposites prepared by incorporating microbial nanofibrils into poly(l-lactic acid)," Current Applied Physics, vol. 9, no. 1, pp. S69-S71, 2009.

[14] B. Li, S. Pan, H. Yuan, and Y. Zhang, "Optical and mechanical anisotropies of aligned electrospun nanofibers reinforced transparent PMMA nanocomposites," Composites Part A: Applied Science and Manufacturing, vol. 90, pp. 380-389, 2016.

[15] X.-F. Wang, Z.-M. Huang, and L.-S. Chen, "Comparison study on transparent composites with different patterns of nanofiber reinforcement," Fibers and Polymers, vol. 12, no. 3, pp. 359-365, 2011.

[16] D. Chen, R. Wang, W. W. Tjiu, and T. Liu, "High performance polyimide composite films prepared by homogeneity reinforcement of electrospun nanofibers," Composites Science and Technology, vol. 71, no. 13, pp. 1556-1562, 2011.

[17] E. Özden-Yenigün, Y. Z. Menceloğlu, and M. Papila, "MWCNTs/P(St-co-GMA) composite nanofibers of engineered interface chemistry for epoxy matrix nanocomposites," ACS Applied Materials and Interfaces, vol. 4, no. 2, pp. 777-784, 2012.

[18] J. Chen, X. Li, W. Cui, C. Xie, J. Zou, and B. Zou, "Fibrous composites with anisotropic distribution of mechanical properties after layer-by-layer deposition of aligned electrospun fibers," Advanced Engineering Materials, vol. 12, no. 9, pp. B529-B538, 2010.
[19] S. Asano, A. Ohmory, A. Akiyama, M. Osawa, K. Shizuka, and M. Kouno, "Heat resistant organic synthetic fibers and process for producing the same," US, US 4758649 A[P], 1988.

[20] N. N. Machalaba and K. E. Perepelkin, "Heterocyclic aramide fibers-production principles, properties and application," Journal of Industrial Textiles, vol. 31, no. 3, pp. 189-204, 2002.

[21] Y.-J. Wu, J. C. Seferis, and V. Lorentz, "Evaluations of an aramid fiber in nonwoven processes for honeycomb applications," Journal of Applied Polymer Science, vol. 86, no. 5, pp. 1149-1156, 2002.

[22] B. He, J. Li, and Z. Pan, "Morphology and mechanical properties of MWNT/PMIA nanofibers by electrospinning," Textile Research Journal, vol. 82, no. 13, pp. 1390-1395, 2012.

[23] B. He, L. Tian, J. Li, and Z. Pan, "Effect of hot-stretching on morphology and mechanical properties of electrospun PMIA nanofibers," Fibers and Polymers, vol. 14, no. 3, pp. 405-408, 2013.

[24] M. Baiardo, G. Frisoni, M. Scandola et al., "Thermal and mechanical properties of plasticized poly(L-lactic acid)," Journal of Applied Polymer Science, vol. 90, no. 7, pp. 1731-1738, 2003.

[25] R. Auras, B. Harte, and S. Selke, "An overview of polylactides as packaging materials," Macromolecular Bioscience, vol. 4, no. 9, pp. 835-864, 2004.

[26] M. Murariu and P. Dubois, "PLA composites: from production to properties," Advanced Drug Delivery Reviews, vol. 107, pp. 1746, 2016. 

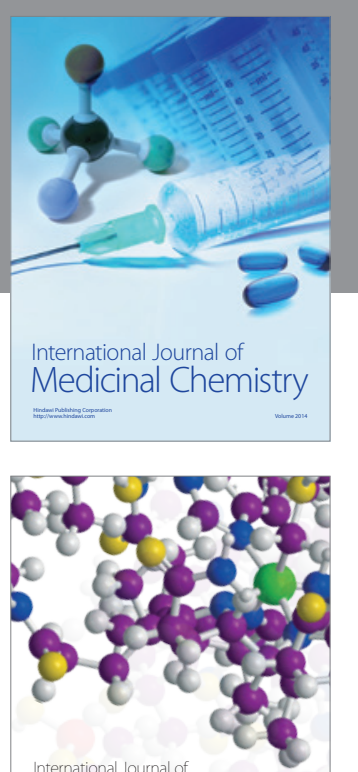

Carbohydrate Chemistry

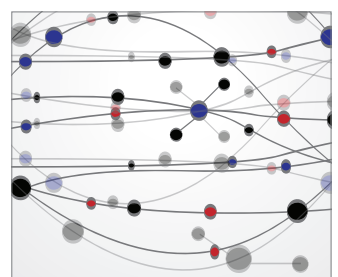

The Scientific World Journal
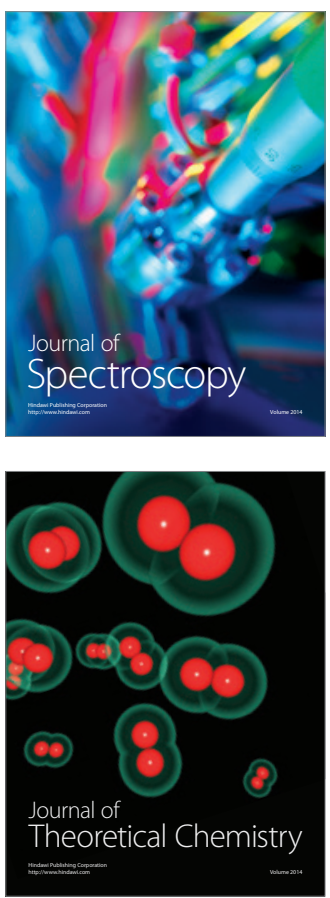
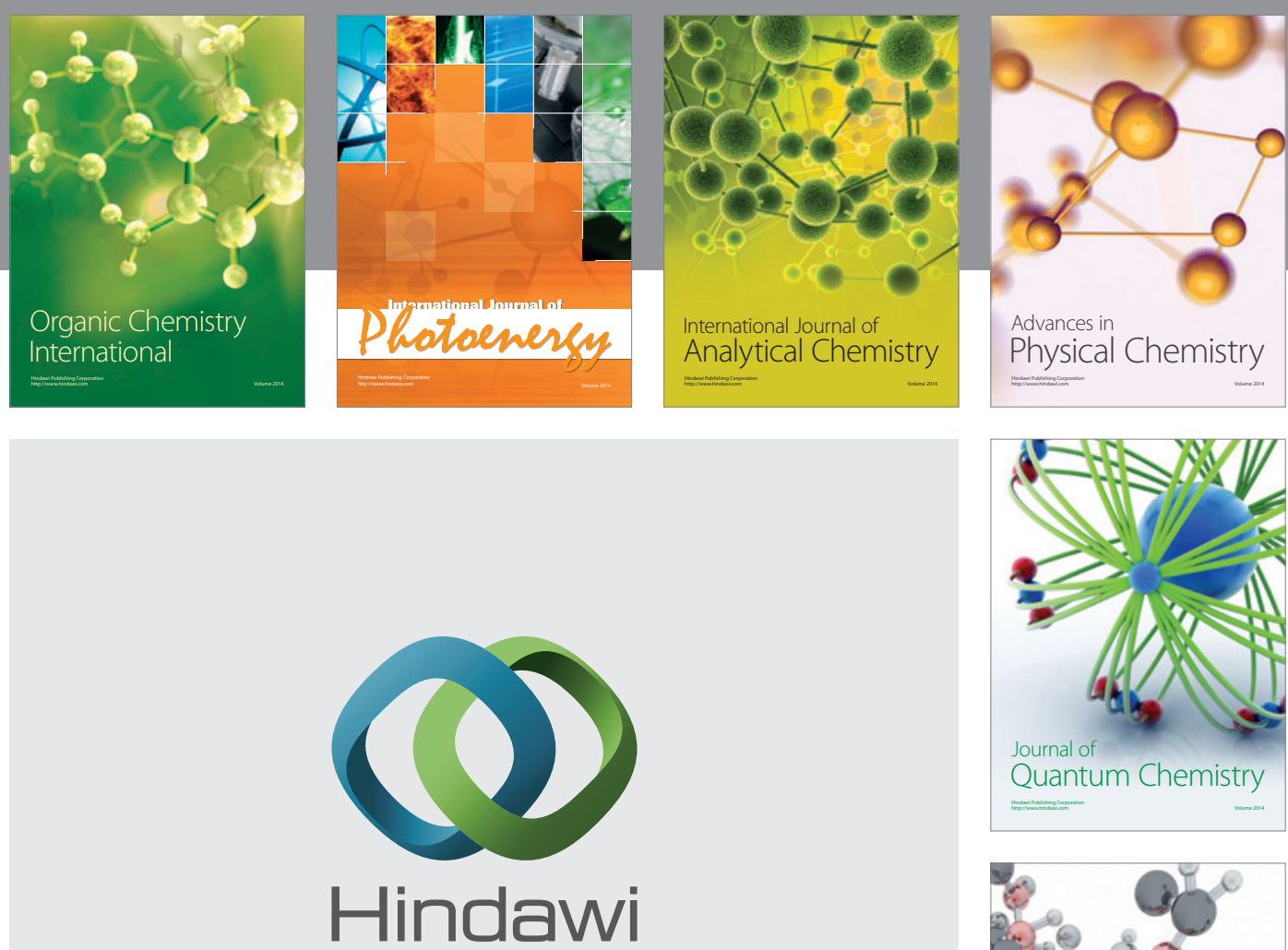

Submit your manuscripts at

https://www.hindawi.com

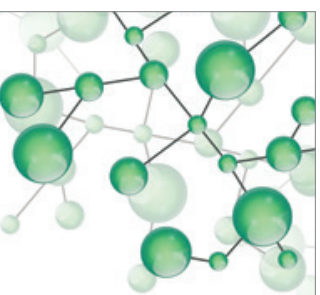

International Journal of

Inorganic Chemistry
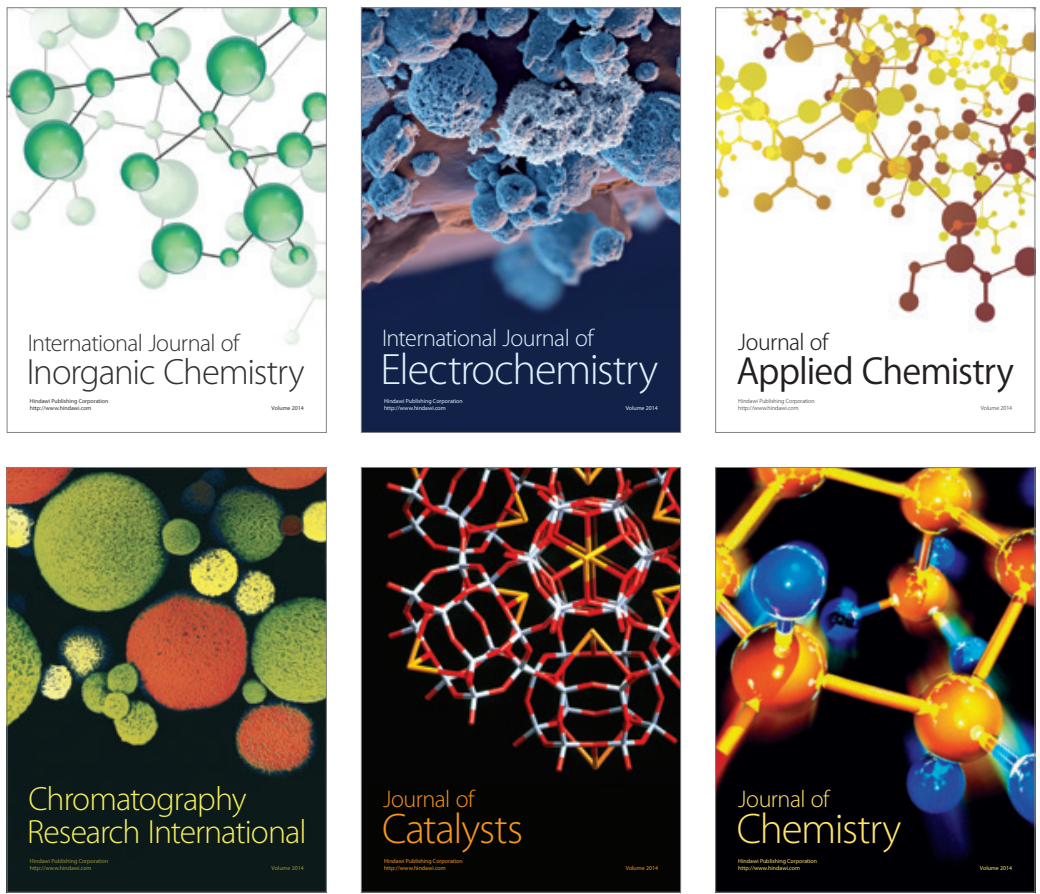

Journal of

Applied Chemistry
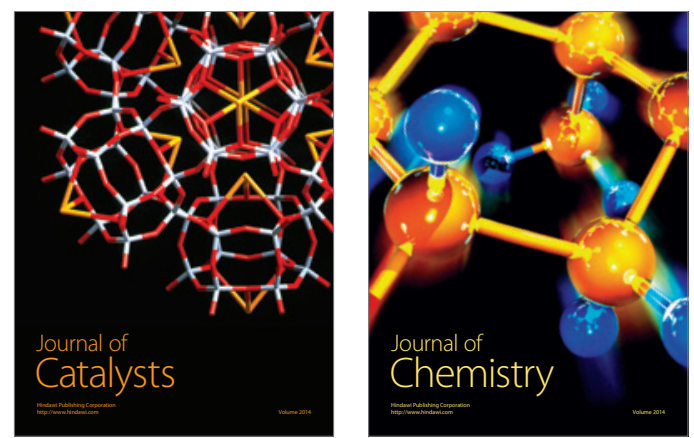
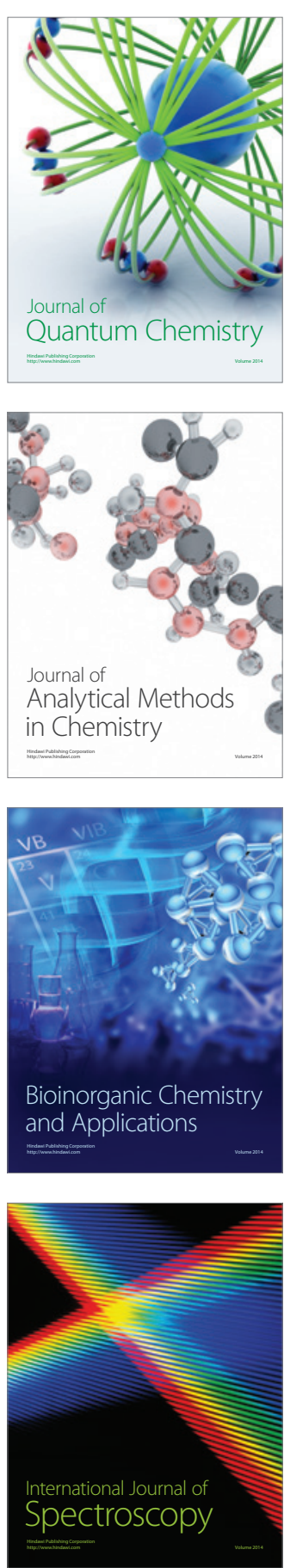